\title{
FUZZY LOGIC CONTROLLER BASED THREE- PHASE PWM AC CHOPPER FED INDUCTION MOTOR DRIVE WITH HBCC TECHNIQUE
}

\author{
Raja Reddy. Duvvuru \\ Associate Professor, Electrical and Electronics Engineering Department, \\ Malla Reddy Engineering College (A), Hyderabad, Telangana, India \\ T.S.K. Manoj \\ PG Scholar, Electrical and Electronics Engineering Department, \\ Malla Reddy Engineering College (A), Hyderabad, Telangana, India

\section{A.V. Sudhakara Reddy} \\ Associate Professor, Electrical and Electronics Engineering Department, \\ Malla Reddy Engineering College (A), Hyderabad, Telangana, India

\section{Rajesh Reddy. Duvvuru} \\ Assistant Professor, Electrical and Electronics Engineering Department, \\ Narayana Engineering College, Gudur, Andhra Pradesh, India

\section{Ch. Narendra Kumar} \\ Associate Professor, Electrical and Electronics Engineering Department, \\ Malla Reddy Engineering College (A), Hyderabad, Telangana, India

\section{Ch. Rami Reddy} \\ Associate Professor, Electrical and Electronics Engineering Department, \\ Malla Reddy Engineering College (A), Hyderabad, Telangana, India
}

\begin{abstract}
In this work, novel control approach for PFC of 3-ph PWM AC choppers is designed. The control strategy is based on the HBCC method fed 3-ph squirrel cage Induction Motor with flexible starting and smooth speed control operating modes. The main aim of this work is to get the IM drive's input PFC to work under various operating conditions. PFC is achieved by driving the actual 3-ph supply with a constant current and the corresponding reference currents, which are produced in phase with the supply voltages using the HBCC technique. The suggested control strategy has two loops, an inner loop and an outer loop. The amplitude of the supply reference current arising from either the speed controller or the starting controller is the output of the inner loop, which is PWM signals from the ac chopper and the output of the outer loop is the
\end{abstract}


amplitude of the supply reference current arising from either the speed controller or the starting controller. As a consequence, the proposed system is simple, dependable, reliable and economical. Mathematical analysis of the drive mechanism is performed. The input LC filter's components are designed using frequency response. The proposed control technique is analysed, measured and simulation of results are obtained in a variety of testing circumstances.

Key words: Hysteresis Band Current Control (HBCC), Induction Motor drive (IM), Power Factor Correction (PFC), Pulse Width Modulation (PWM), three-phase AC chopper

Cite this Article: Raja Reddy. Duvvuru, T.S.K. Manoj, A.V. Sudhakara Reddy, Rajesh Reddy. Duvvuru, Ch. Narendra Kumar and Ch. Rami Reddy, Fuzzy Logic Controller Based Three-Phase PWM AC Chopper Fed Induction Motor Drive with HBCC Technique, International Journal of Electrical Engineering and Technology (IJEET), 12(5), 2021, pp. 227-236.

https://iaeme.com/Home/issue/IJEET?Volume=12\&Issue $=5$

\section{INTRODUCTION}

$\mathrm{AC}$ voltage regulators, conjointly called AC voltage controllers, square measure employed in many various applications that need a controlled AC voltage, simply a number of examples square measure rheostat circuit lighting management, residential and industrial heating, speed management, and soft starters for induction motors [1], [2]. These regulators are available variety of topologies and management mechanisms for single-phase applications. Thyristors (i.e. chemical element Controlled Rectifiers) ar utilized as power switches within the ON/OFF management methodology to repeatedly connect/disconnect the load circuit to/from the AC voltage provide. The feeding voltage is connected for a couple of integral cycles before disconnection. The number of conducted and discontinuous cycles determines the RMS magnitude of the output. Unwanted sub harmonic elements, on the opposite hand, may be created [3]. This technology is restricted to heating and temperature management systems thanks to the facility source's separation at low demand levels. Dynamical the firing regulates the output of the AC voltage controller within the PA system. A single-phase regulator with PA regulation uses 2 thyristors joined back to back between the AC supply and also the load circuit, whereas a 3-phase regulator uses three pairs of SCRs. [4], [5] outline soft beginning for a thyristorized voltage regulator-driven induction motor (IM). Artificial techniques ar utilized. In [6] beginning of AN AC motor's output voltage within the ramp technique, the voltage rises bit by bit.

However an outsized range of sensors, likewise as detection of zero crossings (ZCD). These controllers necessitate circuits, that create them complicated. moreover, it's expensive. Moreover, the $\mathrm{AC}$ voltage thyristorized important harmonics and low input ar provided by the controller. Not withstanding the load is pure resistive, power issue (PF) is very important. AC voltage regulators may be controlled victimisation PWM with fashionable power switches. In terms of harmonics, performance may be improved. By adjusting the duty magnitude relation of the chopper IGBTs, the RMS worth of the motor voltage may be controlled, and also the motor speed may be adjusted likewise. The chopper during this image is in buck mode. There ar modes for bucking and boosting. (13) Single-phase PWM AC chopper's performance may be created even higher by removing the voltage harmonics and ways. Balanced 3 section curved currents may be achieved victimisation the HBCC approach. the facility circuit of this method, on the opposite hand, employs six IGBTs with six gate pulses, creating the system complicated and dear. this method conjointly contains a low input PF. Researchers have paid very little 
attention to the greenhouse emission of three-phase PWM AC choppers, despite the very fact that single-phase PWM AC choppers were the centre of their study. greenhouse emission is needed by international standards [30], [31]. On the opposite hand, for management simplicity and dependableness, a discount within the range of semiconductor devices and also the introduction of novel management techniques is needed. The HBCC methodology is employed during this study to develop a brand new management method for greenhouse emission of a 3 section PWM AC chopper. it's recommended that to use completely different in operation modes. the facility issue is that the magnitude relation of an entire electrical installation's helpful (Real) power $(\mathrm{kW})$ to the entire (apparent) power $(\mathrm{kVA})$ consumed.

It's a metric for decisive however effectively electricity is born-again into helpful work output. Unity or one is that the ideal power issue. If the quantity is a smaller amount than one, a lot of effort is required to finish the task. once the facility issue is a smaller amount than one, the "missing" power is said as reactive power, that is unluckily needed to provide the magnetising field needed by motors and alternative devices, alternative inductive masses to finish their tasks. it's conjointly potential to interpret reactive power as wattless, magnetising, or wasted power and it adds to the electrical load, client likewise because the provide chain. AN inductive load, like AN induction motor, an influence electrical device or a ballast in an exceedingly lamp, a fastening set, induction chamber, a discharge, a rectifier, AN electrical converter, a variable speed drive, and a switched mode power provide further electronic masses, like lights Inductive masses cause a poor power issue.

The p.f can be uttered in two ways:

1. Power factor $(\mathrm{pf})=$ Reall power $(\mathrm{W})$ divided by the apparent power (VA),

2. Power factor $(\mathrm{pf})=$ The cosine of the angle between useful power and total power $=\cos \varnothing$.

The following are some of the advantages that can be obtained by adopting proper power factor correction:

a. Environmental benefit.

b. Lower energy usage as a result of increased energy efficiency.

c. Less electricity usage equals less greenhouse gas emissions and less depletion of fossil fuels. Stations of energy

d. Electricity bill reductions

e. Additional kVA from the existing power source I2R loss reduction.

The end result will be a distorted current waveform. Some inverters are marketed with an influence factor of higher than 0.95 , compared to verity power factor between 0.5 and 0.75 . The cosine angle gives us 0.95 between voltage and current, but ignores the actual fact that this waveform isn't rectangular. As a result, larger losses result from the discontinuity. An inductive load generator necessitates to make a force field. For instance consider power factor of single phase induction motor. the present flowing would be in-phase with the voltage if the motor offers a very resistive load to the provision. this is often an example of creativity. But this can be not true. The magnet within the motor isn't in phase with the magnetising current. The magnetising current is that the current that makes the flux within the iron. When it's not present, it causes the loss of flux. The magnetizing current doesn't contribute to the work output of the motor. 


\section{SYSTEM DESCRIPTION AND OPERATING PRINCIPLE}

The power switch of Figure 1 illustrates a schematic diagram of a proposed three-phase AC PWM Chopper that supplies power to the IM. There are only four power electronics in the Chopper. The figure shows the switches (S1, S2, S3 and S4). S1, S2 and S3 are three power switches. On the other hand, the ignition switch (S4) is connected in parallel through a multiphase bridge.

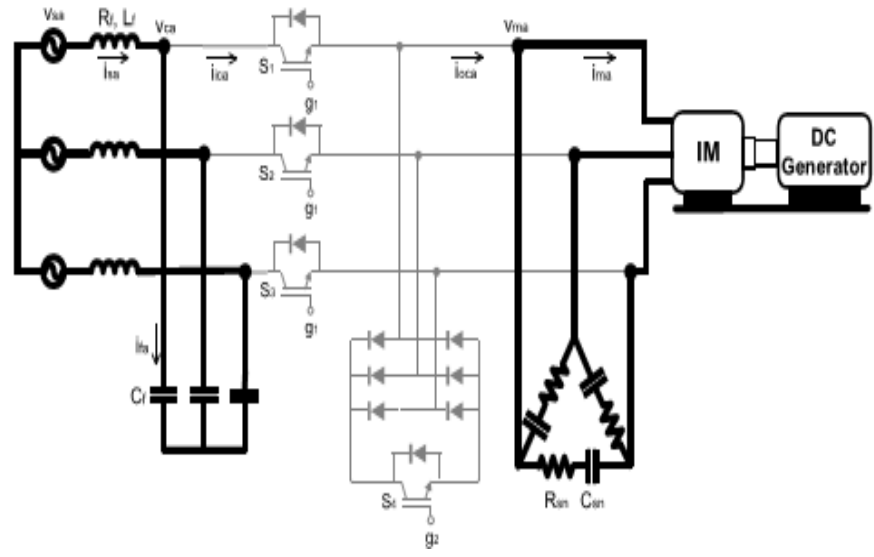

Figure 1. Schematic diagram of a proposed three-phase AC PWM Chopper

\section{PROPOSED CONTROL STRATEGY}

The future control plan has 3 main control objectives: flexible starting, smooth Speed control, and input power factor correction (PFC). The applied voltage across the IM terminals is regulated using an AC chopper in this strategy. The future control strategy is illustrated schematically in Fig.2. Two control loops are present. HBCC is used in the inner control loop. This technique is reliant on the ability to monitor the environment



Figure 2 Proposed HBCC is used in the inner control loop

\section{A. Soft Starting Mode}

The flexible starting mode's function is to produce the supply current's reference value in such a way that the IM's starting current is limited to a predetermined value. The actual current of 
IM (Im) is determined, and the RMS value of the current is calculated using the RMS detector. The motor current (Im) is compared to its command or preset value (Im).

\section{B. Speed Control Mode}

The Controlling the pace of three-phase IMs can be done in a variety of ways. There are two types of approaches. According to the IM's control line, the following are the major categories:

a) Stator-based speed control methods, such as adjusting the applied frequency, applied voltage, and applied Current, Voltage/frequency (v/f) and the number of stator poles monitor

b) Methods for speed control via rotor slip power recovery

\section{PFC Control}

When AC / AC PWM choppers are used in IM drive systems, they are generally negatively affected due to their low PF because they can only change the amplitude of the applied voltage. As a result, the key role of the proposed control strategy is to achieve a high PF of approximately 1 similar to a resistive load. During the start and speed control modes of operation, the recommended PFC strategy is entered. On the other hand, the theory of reactive power management is to implement PFC on the basis of the proposed current control strategy, in which the actual current is adjusted.

\section{FUZZY LOGIC CONTROLLER}

\subsection{Fuzzy Logic}

In recent years, the number and types of fuzzy logic applications have increased considerably. Cameras, camcorders, washing machines, and microwave ovens are examples of consumer products, although industrial process control, medical equipment, and other applications are also included. To understand why fuzzy logic is becoming more and more popular, you need to first understand what fuzzy logic is. There are two definitions of fuzzy logic. Fuzzy logic is a multi-valve logic extended logic system in the strictest sense. However, in a broad sense, fuzzy logic (FL) is almost synonymous with fuzzy set theory, which deals with categories of objects with fuzzy limits and degrees of membership. From this perspective, fuzzy logic is a problem in its limited definition. Fuzzy logic should be regarded as FL in Fuzzy Logic Toolbox software, which means that the definition of fuzzy logic is the most extensive. The basis of fuzzy logic explains the basic concepts behind FL in a very simple and intuitive way. It is worth noting that the basic concept behind FL is the concept of linguistic variables, that is, variables that use words instead of numbers as values. As a result, a large part of Florida's economy is based on tourism. Fuzzy if-then rules or simple fuzzy rules are another basic concept in FL and play a vital role in most applications. Although rule-based systems have been used in AI for a long time, they lack methods for dealing with fuzzy antecedents and consequences. The mechanism is given by the fuzzy logic mechanism. The combination of fuzzy logic with neural computing and genetic algorithms is becoming increasingly common. More generally, fuzzy logic, neural computing, and genetic algorithms can be considered key components of so-called soft computing. Compared to traditional computing, soft computing takes into account the imprecision of the real world.

The guiding ideology of soft computing is to use imprecision, uncertainty, and tolerance for partial truth to achieve processability, flexibility, and low-cost solution costs. Compared to systems built with traditional methods in the future, soft computing may play a larger role in the concept and creation of systems with higher MIQ (machine intelligence). At present, in many soft computing methods, the combination of fuzzy logic and neural computing (leading 
to neuro-fuzzy systems) is the most obvious. Such a system is particularly important in the induction of rules from the observation of fuzzy logic. Dr. Roger Jang has created an excellent method for this purpose, called ANFIS (Adaptive Neuropathic Fibrosis Syndrome). In all respects, the fuzzy logic toolset is excellent. Therefore, fuzzy logic has become an excellent tool for the conception and construction of intelligent systems. The Fuzzy Logic Toolbox is easy to understand and use. Last but not least, it provides readers with an up-to-date, easy-toread introduction to fuzzy logic methods and their generalized applications.

\subsection{Fuzzy Logic Tool Box}

The Fuzzy Logic Toolbox as shown if fig. 3 adds tools for creating systems based on fuzzy logic to the MATLAB technical computing environment. The phases of designing a fuzzy inference system are guided through graphical user interfaces (GUIs). Many popular fuzzy logic approaches, such as fuzzy clustering and adaptive neural fuzzy learning, have functions available. The toolkit allows you to model complicated system behaviours using basic logic rules, which are then put into action in a fuzzy inference system. As a standalone fuzzy inference engine, the toolbox can be used.

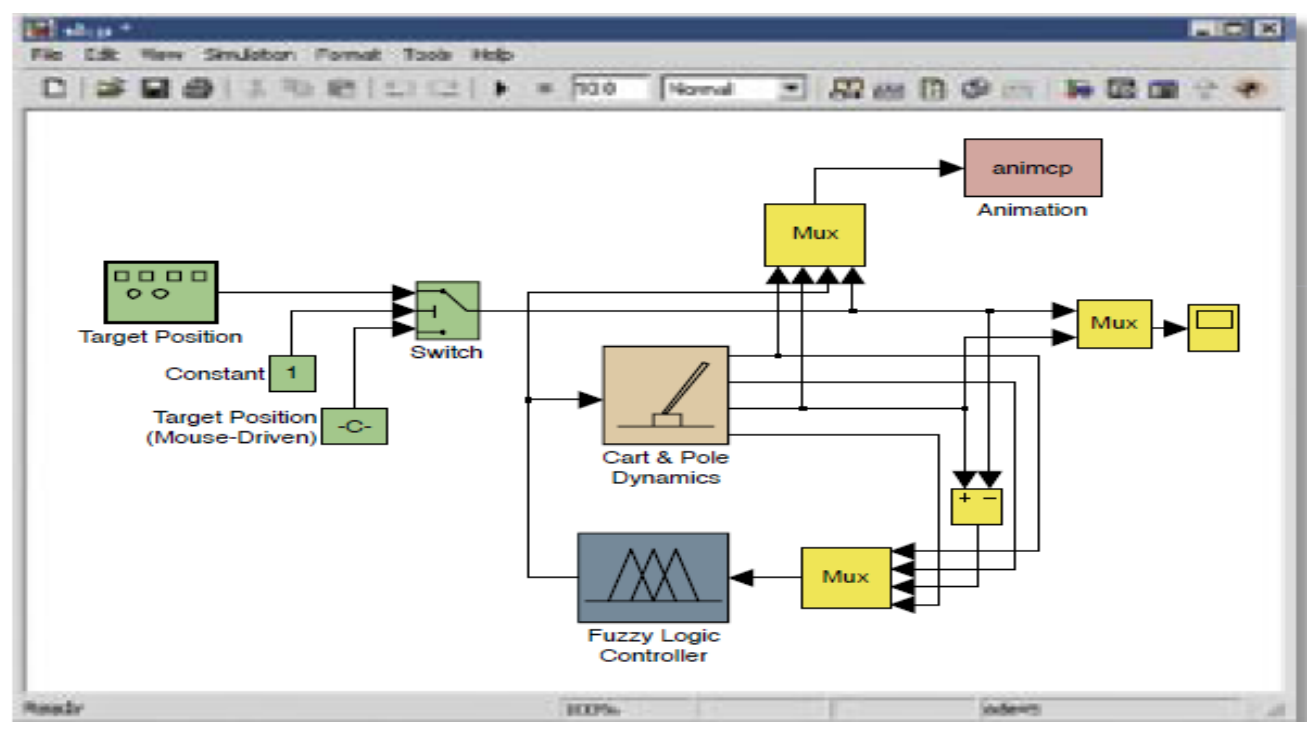

Figure 3. Fuzzy logic tool box

The interface allows you to create traditional fuzzy systems as shown in fig.4and recognize patterns. You can use this toolkit to create and analyze fuzzy inference systems, as well as adaptive neuro-fuzzy inference systems and fuzzy clustering. The toolbox also contains a fuzzy controller module that can be used with Simulink to create and simulate fuzzy logic control systems. Using the graphical user interface (GUI) tool provided by the Fuzzy Logic Toolbox, we will create a simple prompt example in this section. Although the Fuzzy Logic Toolbox can be used entirely from the command line, building a system graphically is generally considerably easier. In the GUI for developing, changing, and watching fuzzy inference systems, there are five basic options. The system's high-level issues are dealt with by the FIS Editor: How many different variables are there in the input and output? Do you know what their names are? The amount of inputs in the Fuzzy Logic Toolbox isn't restricted. Your machine's available RAM may, however, limit the amount of inputs. It may also be difficult to examine the $F$ if there are too many inputs or membership functions. 


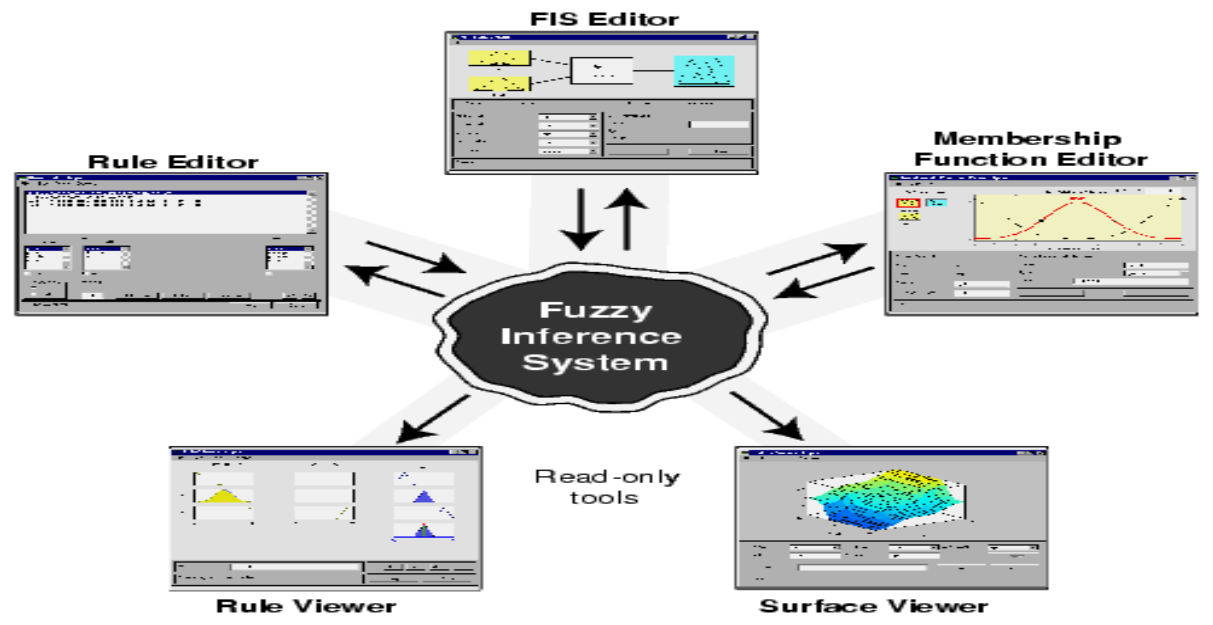

Figure 4. Fuzzy Interface System

The fuzzy control system is a control system based on fuzzy logic as shown in fig 5. The mathematical system analyzes the logical variables of the analog input values according to the logical variables. Logical variables use continuous values between 0 and 1 , while classical or digital logic. discrete values. 1 or 0 .



Figure 5. Fuzzy logic controller

\section{HYSTERESIS BAND CURRENT CONTROL}

Current control strategies play an important role in the development of active parallel filters. The hysteresis band current control method (Anshuman Shukla et al., 2007) is widely used due to its simple implementation as shown in fig.5. The hysteresis band current controller derives the switching signal of the inverter power switch in a way to reduce the current error. The switch is controlled asynchronously to increase and decrease the current flowing to the inductor to follow the reference. When the current through the inductor exceeds the upper limit of hysteresis, the inverter applies a negative voltage to the inductor. This causes the current through the inductor to decrease. Once the current reaches the lower limit of hysteresis, the inverter applies a positive voltage across the inductor, causing the current to rise and repeat the cycle. The three-phase current controller is designed to work independently. They determined that the switching signal of this method has the disadvantage of a variable switching frequency of . In the case of a three-phase active filter that has an isolated neutral point and an irregular modulation pulse position, serious interference between phases (Simone et al. 2000)). These shortcomings lead to input filter design difficulties, noise, and high current ripple. In this 
chapter, a constant frequency hysteresis current driver is proposed for active shunt filter applications.

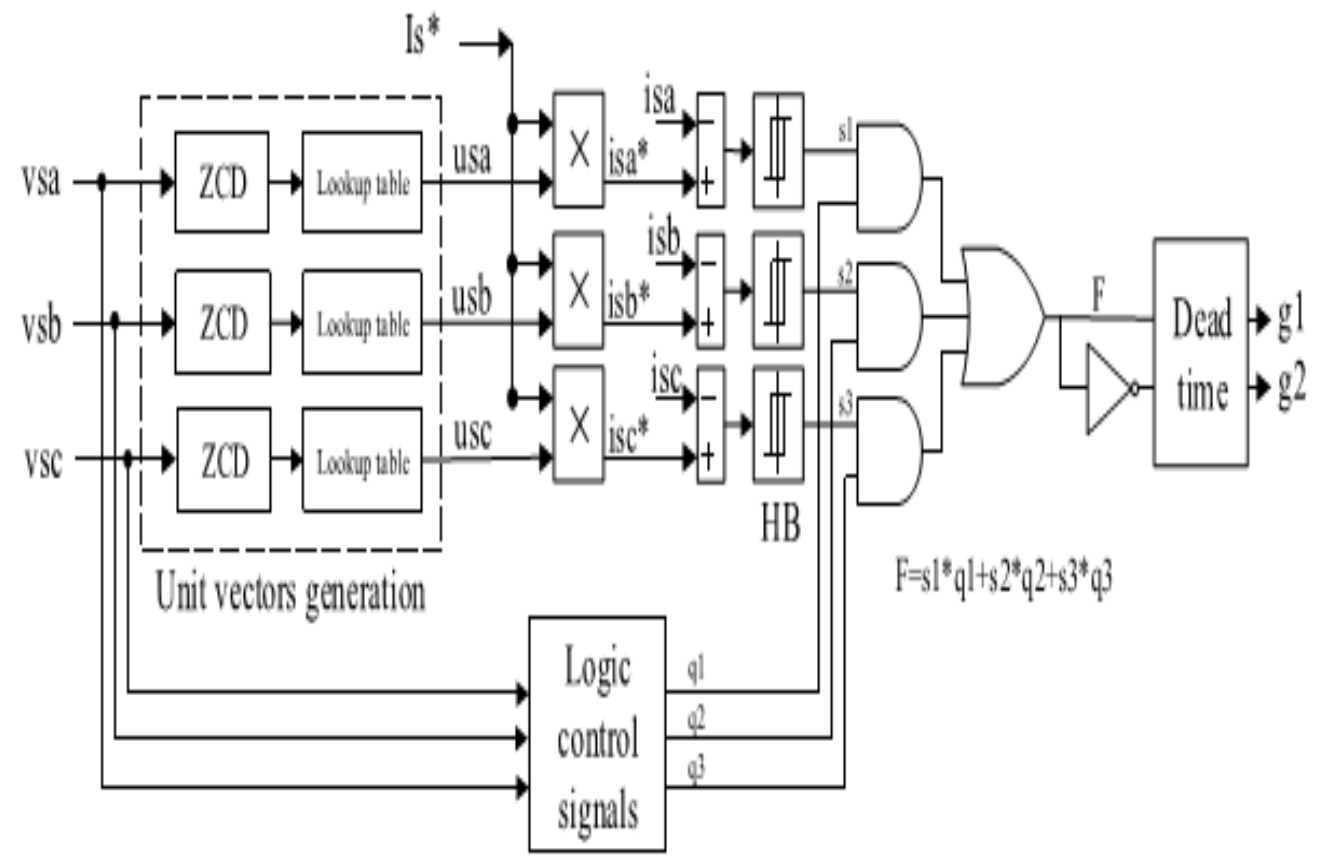

Figure 5. Proposed HBCC technique.

\section{SIMULATION RESULTS}

The proposed AC Chopper was simulated in the MATLAB / Simulink environment and the prototype model was made. The simulation results theoretically verify the proposed control strategy. Although experimental prototypes have been built to confirm the proposed strategy through experiments. Four test cases were verified. The simulation results and the corresponding experimental results are obtained and compared. The following table shows the parameters used in this article.

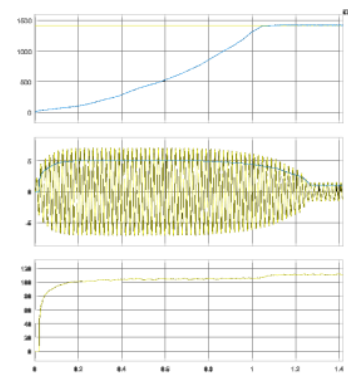

(a) Starting of the motor with Proposed PWM AC Chopper

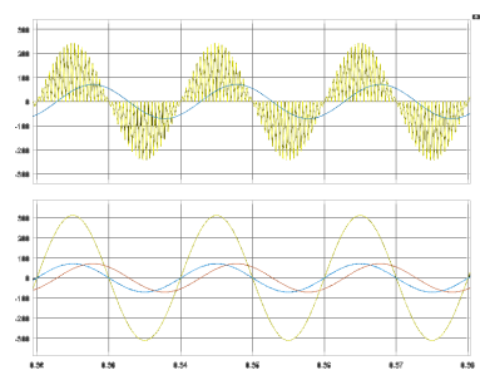

(b) PFC of the drive system during start up of the IM

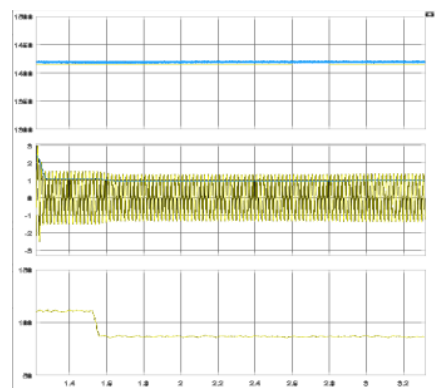

(c) Variation of the motor speed, the current and phase voltage at activation of the speed controller 


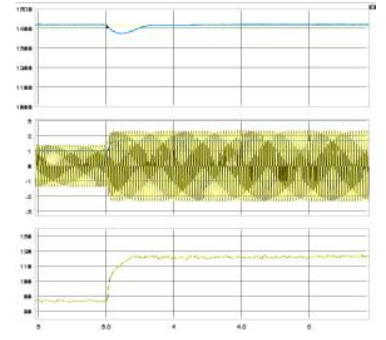

(d) Variation of the motor speed, Current and phase voltage at Step change in the load torque.



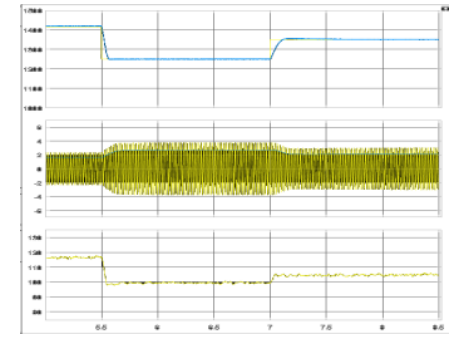

(e) Variation of motor speed, Current and phase voltage at step change in the reference speed

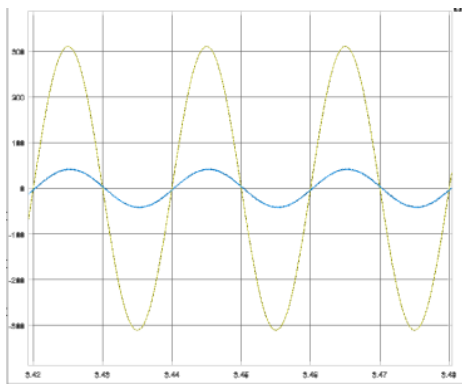

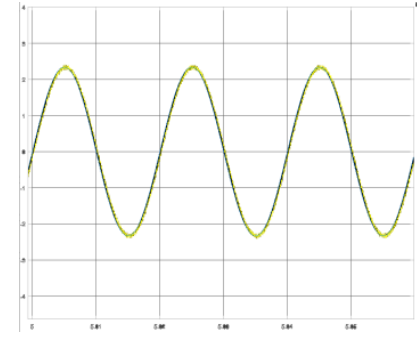

(f) Reference and measured currents of the supply

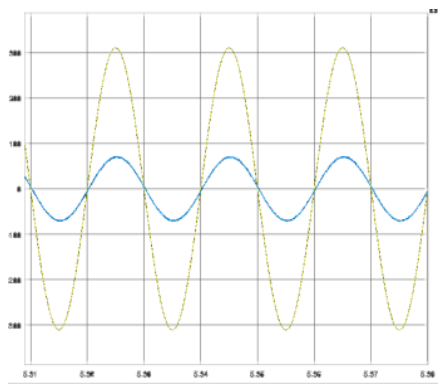

(g) Supply voltage and current at different testing cases of the proposed system

Figure 6 Simulation Results

\section{CONCLUSIONS}

A new PWM AC chopper control strategy feeding the 3- ph IM based squirrel cage was simulated. The main purpose of the control is to correct the input PF according to the different working conditions of the induction motor drive system. By using the HBCC technology to force the actual current from the chopper to track its reference current in phase with the input voltage, the input PFC can be realized. The proposed control strategy uses only two signals PWM to drive active AC chopper switch . The proposed system is simple, reliable and low cost because it only has four IGBT switches. The working principle of the system and the mathematical analysis of are introduced. The system was simulated using MATLAB/SIMULINK, and the laboratory system was implemented. The effectiveness of the control strategy has been tested under startup, reference speed change and load torque change. The results obtained from the experiment and computer simulation work prove the effectiveness of the proposed control strategy under all test conditions. In the three test cases, compared with the proposed technology PFC, the performance of the system without PFC is approximately . The result of comparison shows that the system with the proposed PFC technology has a corrected PF and therefore has better performance. Finally the results of both proposed and conventional topology was observed. From the results we can conclude as FLC actions output accurately as compared with PI controller which results in giving better speed pickup time, less settling time.

\section{REFERENCES}

[1] T. Mishima, Y. Nakagawa, and M. Nakaoka, "A bridgeless BHB ZVS-PWM AC-AC converter for high-frequency induction heating applications," IEEE Trans. Ind. Appl, vol. 51, no. 4, pp. 3304-3315, Jul./Aug. 2015. doi: 10.1109/TIA.2015.2409177.

[2] S. Mahendran, I. Gnanambal, and A. Maheswari, "FPGA-based genetic algorithm implementation for AC chopper fed induction motor," Int. J. Electron, vol. 103, no. 12, pp. 2029-2041, Apr. 2016. doi: 10.1080/ 00207217.2016.1175034. 
Fuzzy Logic Controller Based Three-Phase PWM AC Chopper Fed Induction Motor Drive with HBCC

Technique

[3] F. Luo, H. Ye, and M. H. Rashid, Digital Power Electronics and Applications. Amsterdam, The Netherlands: Elsevier, 2005.

[4] L. Rajaji, C. Kumar, and M. Vasudevan, "Fuzzy and ANFIS based soft starter fed induction motor drive for high performance applications," ARPN J. Eng. Appl. Sci., vol. 3, no. 4, pp. 12 24, Aug. 2008.

[5] A. Gastli and M. M. Ahmed, "ANN-based soft starting of voltage controlled-fed IM drive system," IEEE Trans. Energy Convers, vol. 20, no. 3, pp. 497-503, Sep. 2005. doi: 10.1109/TEC.2004.841522.

[6] M. Muchlas and H. Soetedjo, "Use of the maximum torque sensor to reduce the starting current in the induction motor,' Sensors Transducers, vol. 114, no. 3, pp. 161-169, Mar. 2010.

[7] G. Zenginobuz, I. Cadirci, M. Ermis, and C. Barlak, "Performance optimization of induction motors during voltage-controlled soft starting," IEEE Trans. Energy Convers., vol. 19, no. 2, pp. 278-288, Jun. 2004. doi: 10.1109/TEC.2003.822292.

[8] K. Sundareswaran and P. S. Nayak, "Ant colony-based feedback controller design for softstarter fed induction motor drive," Appl. Soft Comput. , vol. 12, no. 5, pp. 1566-1573, May 2012. doi: 10.1016/j.asoc.2011.12.012.

[9] K. Sundareswaran, N. Rajasekar, and V. T. Sreedevi, "Performance comparison of capacitorrun induction motors supplied from AC voltage regulator and SPWM AC chopper," IEEE Trans. Ind. Electron. , vol. 53, no. 3, pp. 990-993, Jun. 2006. doi: 10.1109/TIE.2006.874256.

[10] S. Jothibasu and M. K. Mishra, "An improved direct AC-AC converter for voltage sag mitigation," IEEE Trans. Ind. Electron., vol. 62, no. 1, pp. 21-29, Jan. 2015. doi: 10.1109/TIE.2014.2334668.

[11] Z. Chen, C. Mao, D. Wang, J. Lu, and Y. Zhou, "Design and implementation of voltage source converter excitation system to improve power system stability," IEEE Trans. Ind. Appl., vol. 52, no. 4, pp. 2778-2788, Jul./Aug. 2016. doi: 10.1109/TIA.2016.2543685.

[12] D. Yildirim and M. Bilgic, "PWM AC chopper control of single-phase induction motor for variable-speed fan application," in Proc. IEEE IECON, Orlando, FL, USA, Nov. 2008, pp. $1337-1342$.

[13] J. M. Flores-Arias, A. M. MuÃśoz, F. D. Perez, V. Pallares-Lopez, and D. Gutierrez, "Voltage regulator system based on a PWM AC chopper converter," in Proc. IEEE ISIE, Gdansk, Poland, Jun. 2011, pp. 468-473.

[14] K. Sundareswaran and A. P. Kumar, "Voltage harmonic elimination in PWM AC chopper using genetic algorithm," IEE Proc. - Electric Power Appl., vol. 151, no. 1, pp. 26-31, Jan. 2004. doi: 10.1049/ip-epa:20040061.

[15] K. Georgakas and A. Safacas, "Modified sinusoidal pulse-width modulation operation technique of an $\mathrm{AC}-\mathrm{AC}$ single-phase converter to optimise the power factor," IET Power Electron., vol. 3, no. 3, pp. 454-464, May 2010. doi: 10.1049/iet-pel.2009.0092.

[16] D.-H. Jang and G.-H. Choe, "Improvement of input power factor in AC choppers using asymmetrical PWM technique,' IEEE Trans. Ind. Electron., vol. 42, no. 2, pp. 179-185, Apr. 1995. doi: 10.1109/41.370384.

[17] P. Sanjit and A. Aurasopon, "Asymmetrical PWM for harmonics reduction and power factor improvement in PWM AC choppers using bee colony optimization," J. Power Electron., vol. 15, no. 1, pp. 227-234, Jan. 2015. doi: 10.6113/JPE.2015.15.1.227. 